\title{
The Variation of Optical Band Gap for ZnO:In Films Prepared by Sol-Gel Technique
}

\author{
Guomei Tang, ${ }^{1}$ Hua Liu, ${ }^{1}$ and Wei Zhang ${ }^{2}$ \\ ${ }^{1}$ School of Mathematics and Computer Science Institute, Northwest University for Nationalities, Lanzhou 730030, China \\ ${ }^{2}$ School of Physical Science and Technology, Lanzhou University, Lanzhou 730000, China \\ Correspondence should be addressed to Guomei Tang; tangguomei07@lzu.cn
}

Received 3 April 2013; Accepted 27 October 2013

Academic Editor: Peter Majewski

Copyright (c) 2013 Guomei Tang et al. This is an open access article distributed under the Creative Commons Attribution License, which permits unrestricted use, distribution, and reproduction in any medium, provided the original work is properly cited.

\begin{abstract}
ZnO:In films with different concentrations ( $0-5$ at.\%) are successfully synthesized on quartz substrates using sol-gel technique. The structure, morphology, and optical properties of $\mathrm{ZnO}$ :In films are investigated by X-ray diffraction, atomic force microscopy, and UV-visible spectrophotometer. It is found that all the films with columnar structural morphology grow along the preferred [001] orientation and the incorporation of indium can improve the crystallinity of $\mathrm{ZnO}$ films. The transmittance of the films is about $80 \%$ in the visible range. A change of the optical absorption edge from blue shift to red shift is observed for ZnO:In films as the doping concentration increases, which means that the optical band gap first increases and then decreases. The blue shift is due to the Burstein-Moss effect. The sharp jump of the absorption edge from blue-shift to red shift is ascribe to the band gap narrowing caused by the merging of the donor and conduction bands of $\mathrm{ZnO}$ :In at high doping concentration.
\end{abstract}

\section{Introduction}

Zinc oxide $(\mathrm{ZnO})$ has been actively studied as a wide band gap oxide semiconductor $\left(E_{g}=3.37 \mathrm{eV}\right)$ for transparent conducting oxide films, short wavelength light-emitting devices, and surface acoustic wave devices. Due to high exciton binding energy $(60 \mathrm{meV})$ and similar structural and optical properties with $\mathrm{GaN}, \mathrm{ZnO}$ has an advantage over $\mathrm{GaN}$ for excitonic device applications. For wide band gap semiconductors, addition of impurities often induces dramatic changes in their electrical and optical properties $[1,2]$, which is very important for their applications. Lu et al. [3] found that the optical energy gap first increased with the electron concentration and then suddenly decreased in Aldoped $\mathrm{ZnO}$ films; the variation was consistent with the Mott criterion for a semiconductor-metal transition. Based on spectroscopic ellipsometry, Kim [4] also found an abrupt jump of the optical absorption edge from blue shift to red shift for ZnO:In films prepared by RF magnetron sputtering. However, few researches reported on the jump of the optical band gap observed directly by UV-visible spectrophotometer for $\mathrm{ZnO}$ :In films prepared by sol-gel technique.
$\mathrm{ZnO}$ films have been prepared by various methods, such as pulsed laser deposition (PLD) [5], metal organic chemical vapor deposition (MOCVD) [6], physical vapor deposition [7], spray pyrolysis [8], and sol-gel technique [9]. Compared with others, sol-gel technique is simple, of low cost, and an advantage of large area deposition. Furthermore, the controllability of the dopant concentration is very easy using sol-gel technique.

In this work, we mainly focus on the variation of the structural and optical properties of $\mathrm{ZnO}$ :In films with increasing dopant concentration. The mechanism of the variation of optical band gap is discussed.

\section{Experimental Procedure}

$\mathrm{ZnO}$ :In films were prepared by sol-gel technique. As a starting material and a dopant, zinc acetate dihydrate $\left(\mathrm{Zn}\left(\mathrm{CH}_{3} \mathrm{COO}\right)_{2} \cdot 2 \mathrm{H}_{2} \mathrm{O}\right)$ and indium nitrate were dissolved in a mixture of 2-methoxyethanol (MOE) and monoethanolamine (MEA) solution. MOE and MEA were the solvent and the stabilizer, respectively. The molar ratio of MEA to zinc acetate was 1.0 and the concentration of zinc acetate 
was $0.7 \mathrm{~mol} / \mathrm{L}$ in the final solution. Indium concentration $\left[\mathrm{In}^{3+}\right] /\left[\mathrm{Zn}^{2+}\right]$ was varied from 0 to 5 at. $\%$. The mixed solution was stirred vigorously at $60^{\circ} \mathrm{C}$ for $2 \mathrm{~h}$ with reflux to yield a clear and homogenous precursor solution, which served as the coating solution after cooling to room temperature. The solution was usually laid aside two days to increase its viscosity, and then the spin-coating was made. Quartz and $\mathrm{Si}$ substrates were employed to deposit $\mathrm{ZnO}$ :In films. Before the deposition, the substrates were ultrasonically cleaned by acetone and absolute alcohol in turn and then dried by blowing nitrogen gas. The solution was dropped onto the substrate, which was rotated at $3000 \mathrm{rpm}$ for $20 \mathrm{~s}$. Afterwards, the films were dried at $350^{\circ} \mathrm{C}$ for $10 \mathrm{~min}$ to evaporate the solvent and remove organic matter. The procedure from coating to drying was repeated three times. Finally, all the films were inserted into a furnace at the same time and annealed in air at $600^{\circ} \mathrm{C}$ for $1 \mathrm{~h}$. ZnO:In films prepared were highly transparent and free from any cracks, voids, and so forth.

The crystalline structure of $\mathrm{ZnO}$ :In films was investigated by a DMax/2400 X-ray diffraction instrument $(\mathrm{Cu}$ $\mathrm{K} \alpha$ radiation, $\lambda=1.5406 \AA$ ). The surface morphology was observed by an atomic force microscopy (SPM-9500). Optical transmittance was measured by the UV-visible spectrophotometer (Shimadzu UV-3101PC) in the wavelength range of $300-800 \mathrm{~nm}$. The films prepared on Si substrates were used to measure the thickness and the refractive index using an ellipsometer (Gaertner Scientific Corporation L116E).

\section{Results and Discussion}

Figure 1 shows X-ray diffraction (XRD) patterns of $\mathrm{ZnO}$ :In films with different dopant concentrations ( $\operatorname{In} / \mathrm{Zn}=0,1,2$, 3 , and 5 at.\%). A strong (002) diffraction peak and a weak (004) diffraction peak of wurtzite $\mathrm{ZnO}$ structure are clearly observed, which indicates that all the films exhibit preferential orientation growth along [001], that is, perpendicular to the substrate surface. It is also suggested that the surface energy of (001) plane is the lowest in $\mathrm{ZnO}$ crystal [10]. The intensity of the (002) peak sharply increases and then gradually decreases with increasing indium concentration. The film with 1 at.\% indium impurity has the strongest (002) diffraction peak, which is consistent with the others [11]. When the dopant concentration is above 1 at.\%, the crystallinity of $\mathrm{ZnO}$ :In films gradually deteriorates, which may be due to the internal stresses induced by the radius difference of $\operatorname{In}^{3+}(0.81 \AA)$ and $\mathrm{Zn}^{2+}(0.74 \AA)$. No new phases corresponding to indium oxide or other indium compounds are detected even if the concentration of indium increases up to 5 at.\%, which means that the incorporation of impurity atoms does not change the wurtzite structure of $\mathrm{ZnO}$. On the other hand, as can be seen from the inset in Figure 1, the (002) peak position of $\mathrm{ZnO}$ :In films ( $\geq 1$ at.\%) is obviously close to that of $\mathrm{ZnO}$ powder $34.426^{\circ}$, indicating that an appropriate amount of indium impurities can improve the structural properties of $\mathrm{ZnO}$ films. Figure 2 shows the atomic force microscopy (AFM) images of the doped $\mathrm{ZnO}$ film with 1 at. $\%$ indium. The images of other films are similar to them.

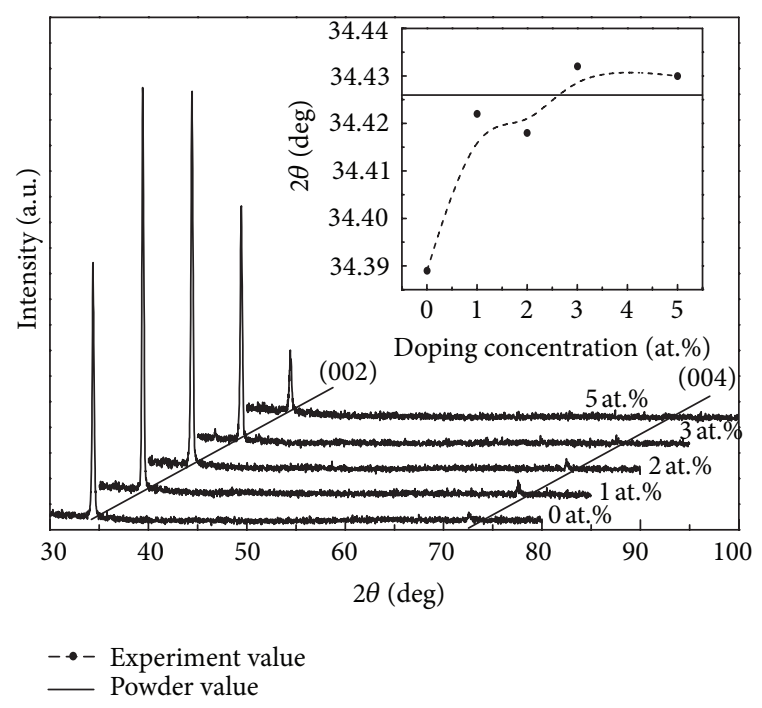

FIGURE 1: XRD patterns of ZnO:In films with different dopant concentrations $(0-5$ at.\%). The inset is the plot of the (002) peak position as a function of indium doping concentration.

TABLE 1: Film thickness, refractive index, and band gap of $\mathrm{ZnO}$ :In films with different doping concentrations.

\begin{tabular}{lccccc}
\hline In concentration (at.\%) & 0 & 1 & 2 & 3 & 5 \\
\hline Film thickness (nm) & 214 & 232 & 244 & 241 & 214 \\
Refractive index & 1.176 & 1.138 & 1.105 & 1.095 & 1.170 \\
Band gap (eV) & 3.157 & 3.216 & 3.202 & 3.197 & 3.151 \\
\hline
\end{tabular}

As seen, the film shows a uniform columnar structure, which can be explained from the XRD pattern.

Figure 3 shows the optical transmission spectra of $\mathrm{ZnO}$ :In films with different doping concentrations. All the films exhibit good optical transmission properties (about $80 \%$ ) in the visible light range. A jump of the ultraviolet absorption edge (around $380 \mathrm{~nm}$ ) from blue shift to red shift can be clearly observed as the doping concentration increases. The absorption coefficients $\alpha$ of $\mathrm{ZnO}$ :In films are given by the transmittance $T$ and the film thickness $d$ using the following formula [12]:

$$
\alpha=\frac{1}{d} \ln \left(\frac{1}{T}\right) .
$$

For the direct band gap semiconductor $\mathrm{ZnO}, \alpha$ obeys the following relationship [13]:

$$
(\alpha h v)^{2}=A\left(h v-E_{g}\right)
$$

where $h v$ is the incidence photon energy, $E_{g}$ is the band gap energy, and $A$ is a constant. A plot of $(\alpha h v)^{2}$ as a function of $h v$ is made to determine $E_{g}$ using the linear fit. The detailed fitting process is shown in Figure 4. As shown in Table 1, the $E_{g}$, derived from the crosspoint at the $h v$-axis with the tangent to $(\alpha h v)^{2}$, sharply increases and then gradually decreases with increasing indium concentration.

As a native n-type oxide semiconductor, $\mathrm{ZnO}$ is doped by indium impurities it is expected that the impurity acts as 

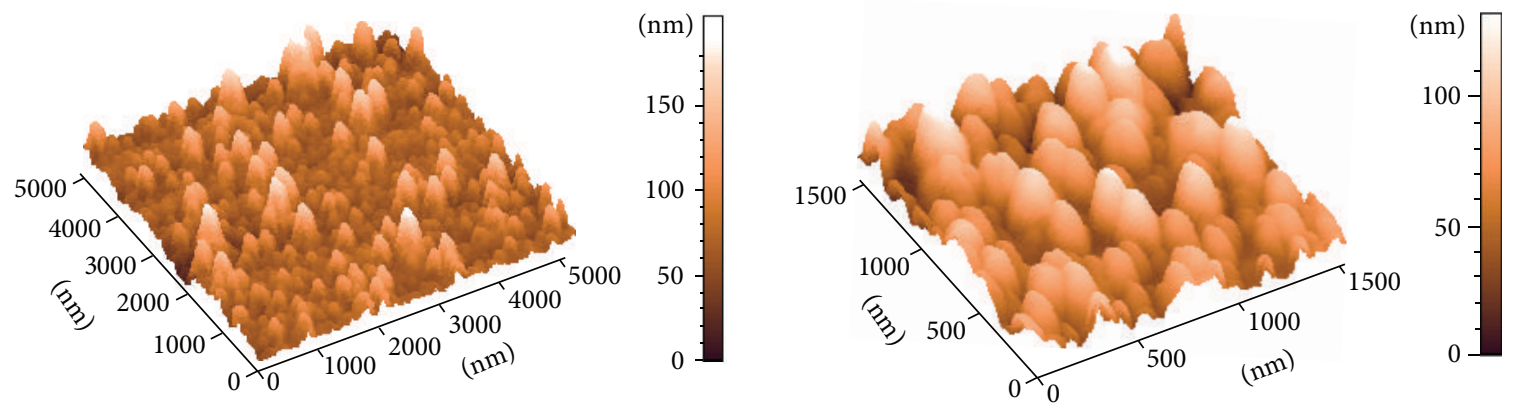

FIgURE 2: Typical AFM images with different magnifications for $\mathrm{ZnO}$ :In thin film doped by 1 at.\% impurity.

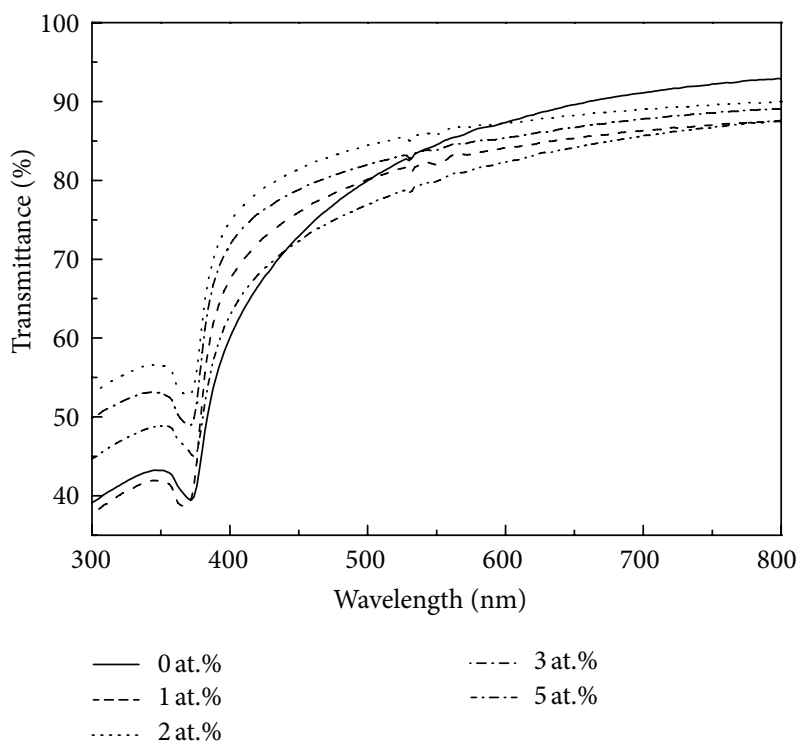

FIGURE 3: Optical transmittance spectra for $\mathrm{ZnO}$ :In films with different dopant concentrations (0-5 at.\%).

the donor by substituting $\mathrm{Zn}$. The excess electrons ionized by the impurities will fill up the conduction band minimum of $\mathrm{ZnO}$. Due to low density of states near the conduction band minimum, electrons excited by the light from the valence band have to occupy the higher energy level. For ZnO:In films with low doping concentrations (0-1 at.\%), the blue shift of the optical absorption edge is due to the abovedepicted reason, which is the Burstein-Moss (BM) effect $[14,15]$. For $\mathrm{ZnO}$ :In films with high doping concentrations, the carrier concentration is quite large ( $>1$ at.\%), and the donor level corresponding to In impurities in $\mathrm{ZnO}$ energy band gradually widens and merges with the conduction band. The merging leads to a sudden decrease of $\mathrm{ZnO}$ band gap. The optical absorption edge rapidly shifts to the large wavelength orientation. Therefore, the red shift of the optical absorption edge should be related to the band gap narrowing led by the semiconductor-metal transition accompanied by the merging of the donor and conduction bands.

\section{Conclusions}

ZnO:In films with different doping concentrations were deposited on quartz substrates by sol-gel technique. All

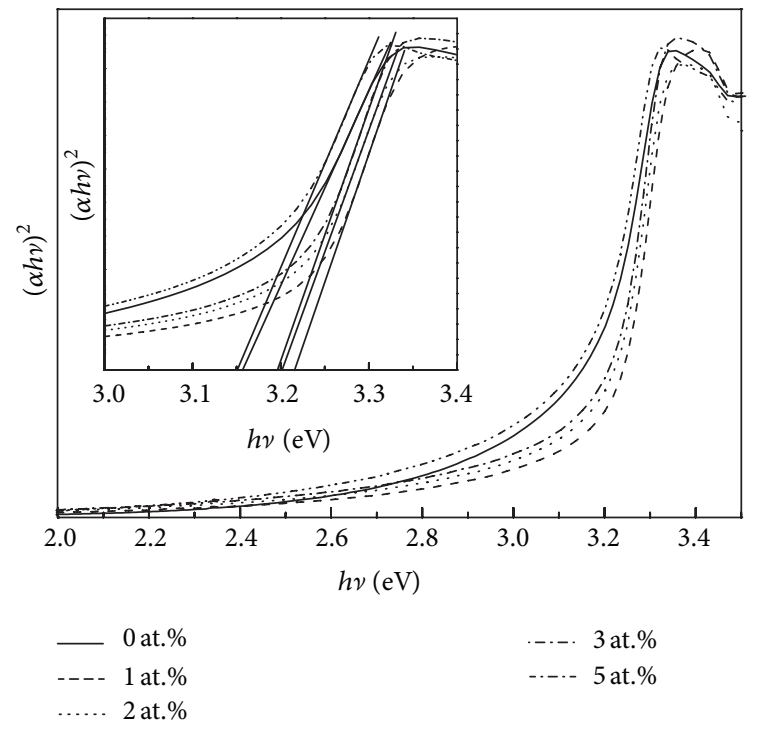

FIGURE 4: The plots of $(\alpha h v)^{2}$ versus $h v$ of $\mathrm{ZnO}$ :In films with different dopant concentrations (0-5 at.\%).

the films grow along the preferred [001] orientation and a proper indium doping can improve the structural property of $\mathrm{ZnO}$ films. The transmittance in the visible region is approximately $80 \%$. The blue shift of the optical absorption edge of ZnO:In films is due to the BM effect. With the increase of doping concentration, the sharp change of the optical absorption edge from blue shift to red shift is ascribed to the semiconductor-metal transition accompanied by the merging of the donor and conduction bands.

\section{Acknowledgment}

The authors would like to acknowledge the financial support by the National Natural Science Foundation of China (no. 31260098), and the Fundamental Research Funds for the Central Universities (no. zyz2012084).

\section{References}

[1] A. Kronenberger, A. Polity, D. M. Hofmann, B. K. Meyer, A. Schleife, and F. Bechstedt, "Structural, electrical, and optical properties of hydrogen-doped $\mathrm{ZnO}$ films," Physical Review B, vol. 86, Article ID 115334, 2012. 
[2] D. Lee, H. Kim, J. Kwon, H. Choi, S. Kim, and K. Kim, "Structural and electrical properties of atomic layer deposited Al-doped ZnO films," Advanced Functional Materials, vol. 21, no. 3, pp. 448-455, 2011.

[3] J. G. Lu, S. Fujita, Z. Z. Ye et al., "Carrier concentration dependence of band gap shift in n-type ZnO:Al films," Journal of Applied Physics, vol. 101, no. 8, Article ID 083705, 2007.

[4] K. J. Kim and Y. R. Park, "Large and abrupt optical band gap variation in In-doped ZnO," Applied Physics Letters, vol. 78, no. 4, pp. 475-477, 2001.

[5] C. Y. Peng, Y. A. Liu, W. L. Wang, J. S. Tian, and L. Chang, “The cooling effect on structural, electrical, and optical properties of epitaxial a-plane $\mathrm{ZnO}: \mathrm{Al}$ on r-plane sapphire grown by pulsed laser deposition," Applied Physics Letters, vol. 101, Article ID 151907, 2012.

[6] J. Jiang, L. Zhu, Y. Wu et al., "Effects of phosphorus doping in $\mathrm{ZnO}$ nanocrystals by metal organic chemical vapor deposition," Materials Letters, vol. 68, pp. 258-260, 2012.

[7] R. García-Gutiérrez, M. Barboza-Flores, D. Berman-Mendoza, R. Rangel-Segura, and O. E. Contreras-López, "Luminescence and structure of $\mathrm{ZnO}$ grown by physical vapor deposition," Advances in Materials Science and Engineering, vol. 2012, Article ID 872597, 5 pages, 2012.

[8] E. Gungor and T. Gungor, "Effect of the substrate movement on the optical properties of $\mathrm{ZnO}$ thin films deposited by ultrasonic spray pyrolysis," Advances in Materials Science and Engineering, vol. 2012, Article ID 594971, 7 pages, 2012.

[9] Y. Sun, J. H. Seo, C. J. Takacs, J. Seifter, and A. J. Heeger, "Inverted polymer solar cells integrated with a low-temperature-annealed sol-gel-derived $\mathrm{ZnO}$ film as an electron transport layer," Advanced Materials, vol. 23, no. 14, pp. 1679-1683, 2011.

[10] C. H. Jia, Y. H. Chen, X. L. Liu, S. Y. Yang, W. F. Zhang, and Z. G. Wang, "Control of epitaxial relationships of $\mathrm{ZnO} / \mathrm{SrTiO}_{3}$ heterointerfaces by etching the substrate surface," Nanoscale Research Letters, vol. 8, article 23, 2013.

[11] M. Miki-Yoshida, F. Paraguay-Delgado, W. Estrada-López, and E. Andrade, "Structure and morphology of high quality indiumdoped $\mathrm{ZnO}$ films obtained by spray pyrolysis," Thin Solid Films, vol. 376, no. 1-2, pp. 99-109, 2000.

[12] Y. Natsume and H. Sakata, "Zinc oxide films prepared by sol-gel spin-coating," Thin Solid Films, vol. 372, no. 1, pp. 30-36, 2000.

[13] J. I. Pankove, Optical Processes in Semiconductors, Prentice-Hall, Englewood Cliffs, NJ, USA, 1971.

[14] E. Burstein, "Anomalous optical absorption limit in InSb," Physical Review, vol. 93, no. 3, pp. 632-633, 1954.

[15] T. S. Moss, "The interpretation of the properties of indium antimonide," Proceedings of the Physical Society B, vol. 67, no. 10, pp. 775-782, 1954. 

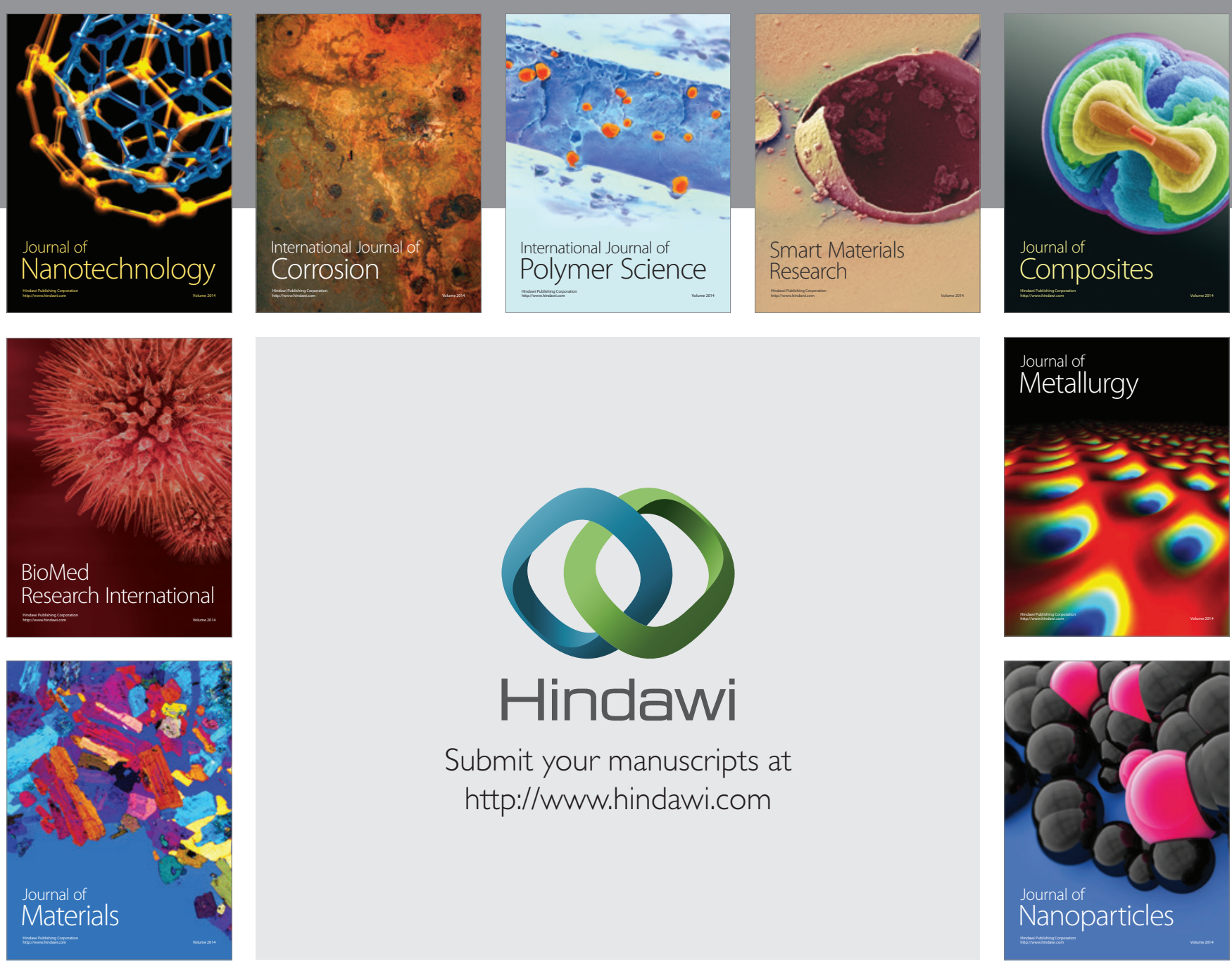

Submit your manuscripts at http://www.hindawi.com
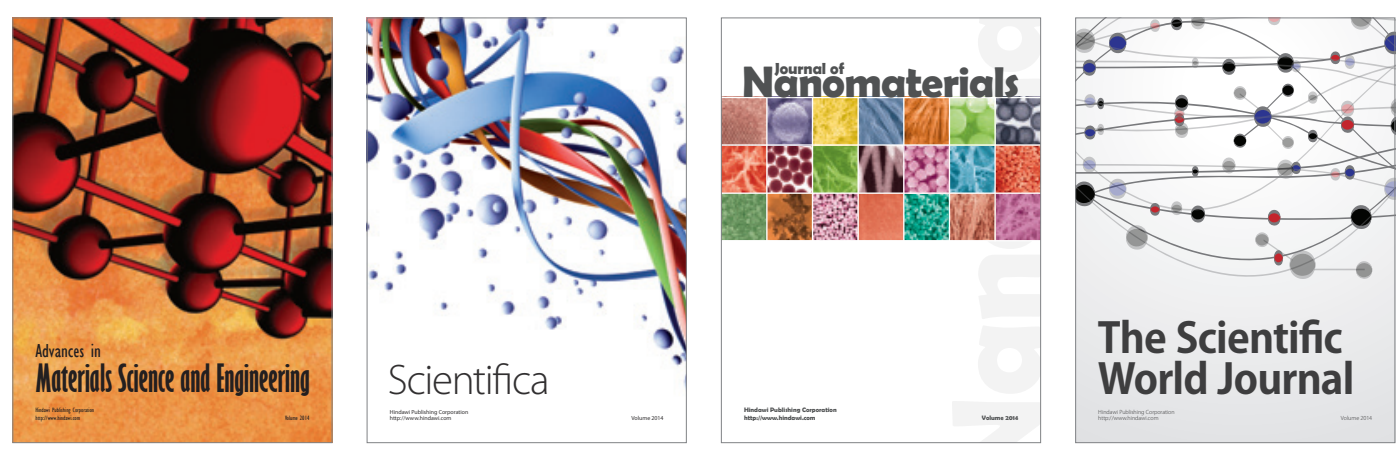

\section{The Scientific World Journal}
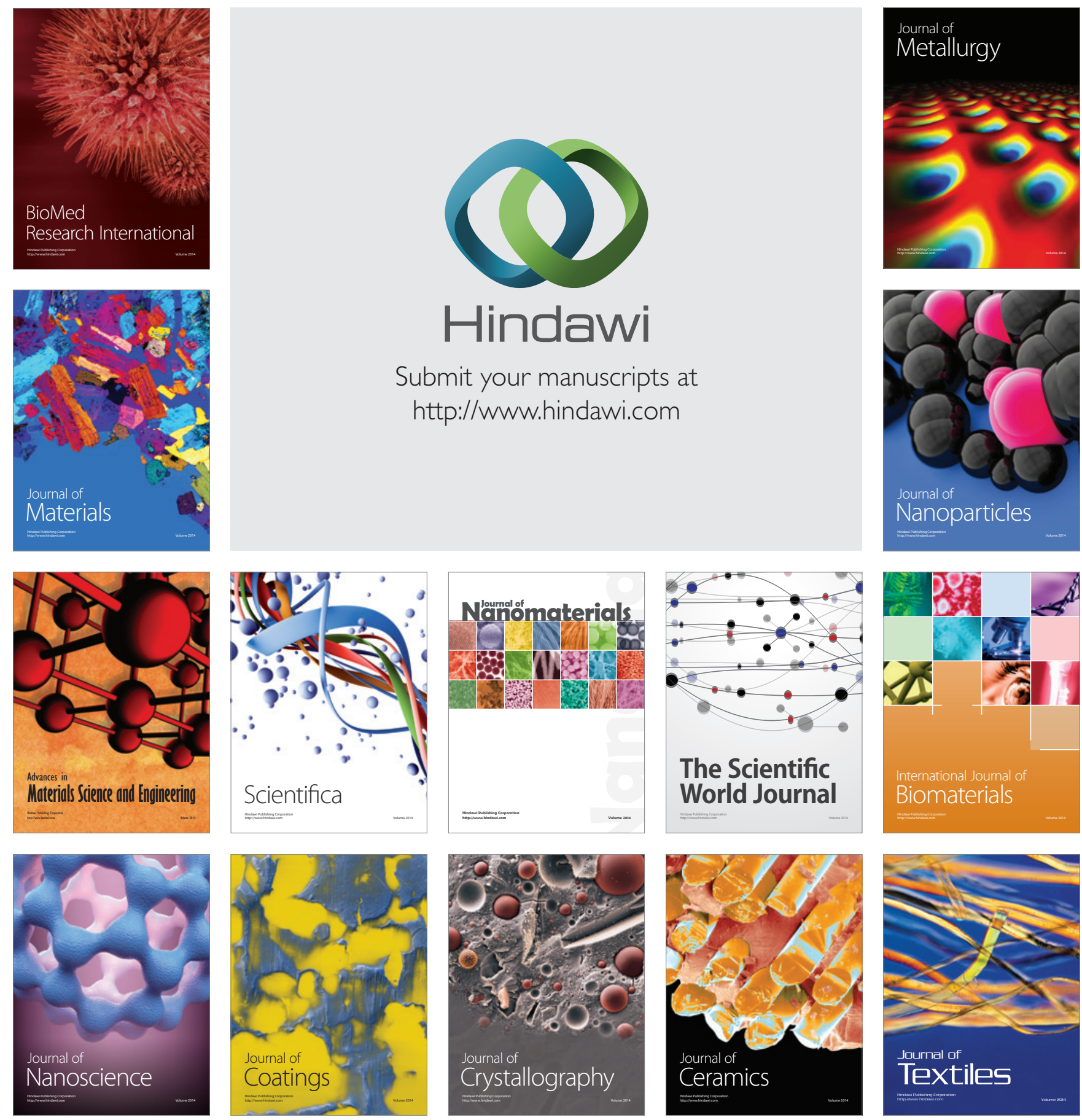